\title{
Test tasks for verification of program codes for calculation of neutron- physical characteristics of the BN series reactors
}

\author{
Georgy Tikhomirov ${ }^{1 a}$, Mikhail Ternovikh ${ }^{1}$, Anton Smirnov ${ }^{1}$, Ivan Saldikov ${ }^{1}$, Rynat Bahdanovich ${ }^{1}$ and Alexander Gerasimov ${ }^{2}$ \\ ${ }^{1}$ National Research Nuclear University MEPhI (Moscow Engineering Physics Institute), Department of Theoretical and Experimental Physics \\ of Nuclear Reactors, 31, Kashirskoe Shosse, 115409, Moscow, Russia. \\ ${ }^{2}$ Institute for Theoretical and Experimental Physics, Department of safe nuclear reactors, 25, Bolshaya Cheremushkinskaya ul., 117218, \\ Moscow, Russia.
}

\begin{abstract}
System of test tasks is presented with the fast reactor BN-1200 with nitride fuel as prototype. The system of test tasks includes three test based on different geometric models. Model of fuel element in homogeneous and in heterogeneous form, model of fuel assembly in height-heterogeneous and full heterogeneous form, and modeling of the active core of BN-1200 reactor. Cross-verification of program codes was performed. Transition from simple geometry to more complex one allows to identify the causes of discrepancies in the results during the early stage of cross-verification of codes. This system of tests can be applied for certification of engineering programs based on the method of Monte Carlo to the calculation of full-scale models of the reactor core of the BN series. The developed tasks take into account the basic layout and structural features of the reactor $\mathrm{BN}-1200$. They are intended for study of neutron-physical characteristics, estimation of influence of heterogeneous structure and influence of diffusion approximation. The development of system of test tasks allowed to perform independent testing of programs for calculation of neutron-physical characteristics: engineering programs JARFR and TRIGEX, and codes MCU, TDMCC, and MMK based on the method of Monte Carlo.
\end{abstract}

\section{Introduction}

The project "Proryv" was initiated in 2012. Its aim was development of new generation nuclear power technologies on the basis of closed nuclear fuel cycle with fast reactors including reactors of $\mathrm{BN}$ series. Specialized program codes should be developed and improved for this project. Validation of code complexes does not yet have a clearly defined methodology, mainly due to the inability to create for them a representative experimental base. We have to use the separate verification of major program codes included in such complexes. Test tasks are widely used for this purpose. Unfortunately, there are not so much test tasks dealing with fast reactors at the moment $[1,2]$.

\section{Classification of test tasks}

Test tasks on neutron physical calculation can be divided into several categories, depending on the method of definition of the geometry, cross sections, and composition or applications and information sources:

1. Purely calculational (mathematical) test with specified coefficients for the solution of equations that has no real prototype (M - Mathematical test);
2. Calculation test, having a real reactor prototype with full initial data and all specified the necessary macro- and micro-cross sections and constants, which provides accurate solution (MP - Mathematical test with Prototype);

3. Test that has a real reactor prototype, however without required cross-sections. Concentrations of nuclides approximately correspond the real compositions. Some other characteristics can also be simplified in comparison with the prototype (PO Prototype-Operational test);

4. Test, which simulates a real reactor without required cross sections. These tests are sometimes called operational tests. The concentrations of radionuclides and / or other data accurately correspond to any real state of the simulated reactor. As a rule, values of calculated functionals for these tests are based on the experimental data. They are used to validate the program codes. Tests of this type sometimes are not intended for public distribution, especially in the case of large efforts spent for evaluation of experimental data and in cases where there are potential buyers $(\mathrm{O}$ - Operational test).

Recently, calculation tests are often used instead of experimental tests because of high expenses of the lasts.

\footnotetext{
a Corresponding author: gvtikhomirov@mephi.ru
} 


\section{System of tests}

The test system presented in this paper belongs to computing tests with $\mathrm{BN}-1200$ as a prototype. The test system includes three consecutive tests that simulate different geometric models: fuel rods, fuel assemblies, and the core. Successive transition from a simple to a more complex geometry allows to identify the causes of discrepancies in the results on the early stage of code cross verification.

\subsection{Test No. 1: fuel element}

The purpose of this task is to calculate the burnup in a fuel rod as part of determining the characteristics of the reactor BN-1200. The task is solved both in a homogeneous and in heterogeneous geometry for a variety of types of plutonium isotopic compositions.

We consider the central fuel cell of fuel assembly of BN-1200 (Figure 1). Simple geometry allows to study in detail the calculation of burnup, compare models and approximations used in various calculation codes.

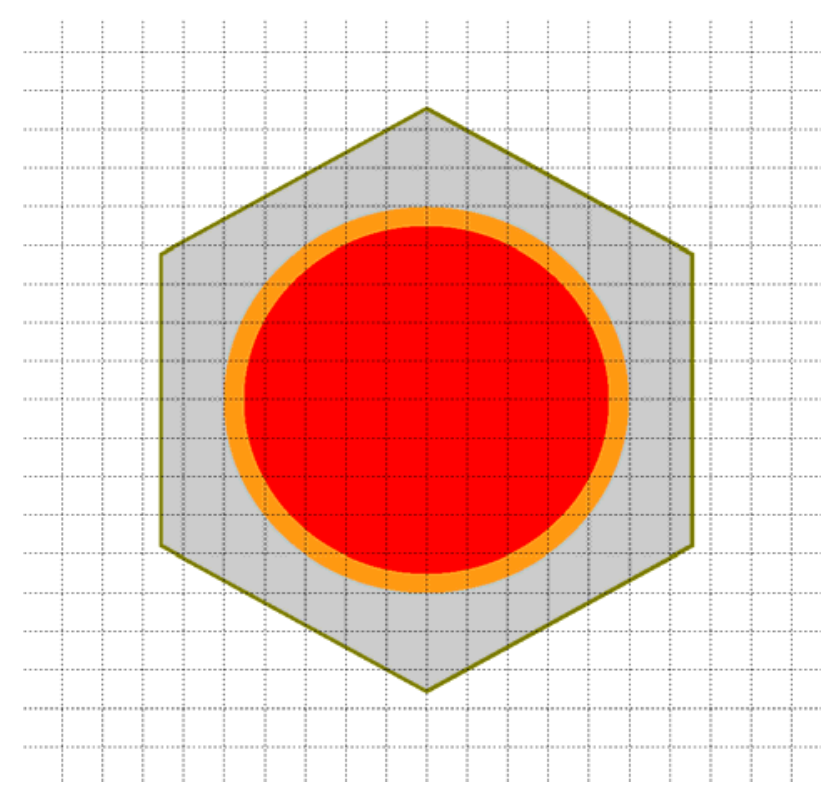

Fig. 1. Fuel element

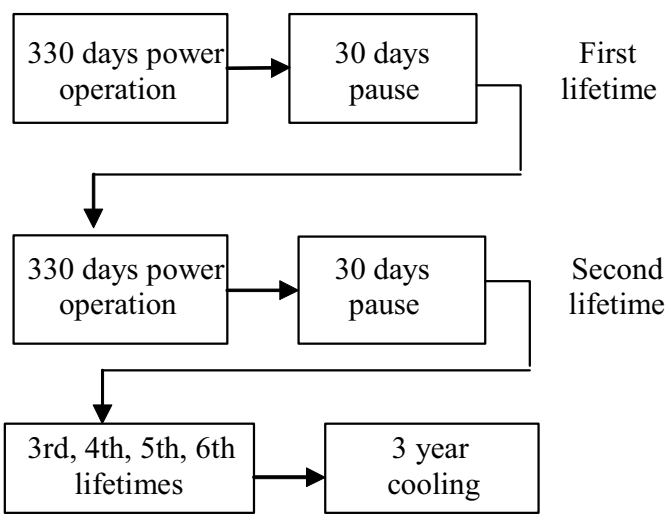

Fig.2. Structure of the calculated cycle
Calculations were performed for 6 fuel lifetimes with power operation guring 330 days and 30-days interval after power operatuin within the lifetime. So, the whole lifetime duration 360 days. The whole cycle considered for calculation (Figure 2) was about 9 years including 3 years cooling. Time steps $3 \times 10+6 \times 50$ days were used for calculations. Mixed nitride fuel was used in this calculation model. 28 isotopes were taken into account: ${ }^{235} \mathrm{U},{ }^{236} \mathrm{U},{ }^{238} \mathrm{U} ;{ }^{237} \mathrm{~Np},{ }^{239} \mathrm{~Np} ;{ }^{238} \mathrm{Pu},{ }^{239} \mathrm{Pu},{ }^{240} \mathrm{Pu},{ }^{241} \mathrm{Pu}$, ${ }^{242} \mathrm{Pu} ;{ }^{241} \mathrm{Am},{ }^{242 \mathrm{~m}} \mathrm{Am},{ }^{243} \mathrm{Am} ;{ }^{242} \mathrm{Cm},{ }^{243} \mathrm{Cm},{ }^{244} \mathrm{Cm}$, ${ }^{245} \mathrm{Cm},{ }^{14} \mathrm{~N},{ }^{23} \mathrm{Na},{ }^{56} \mathrm{Fe},{ }^{52} \mathrm{Cr},{ }^{59} \mathrm{Ni},{ }^{96} \mathrm{Mo},{ }^{93} \mathrm{Nb},{ }^{55} \mathrm{Mn},{ }^{10} \mathrm{~B}$, ${ }^{11} \mathrm{~B},{ }^{12} \mathrm{C}$. To account for the impact on the absorption of fission products, effective fission product can be used.

\subsection{Test No. 2: fuel assembly}

Calculation model of fuel assembly of the BN-1200 is considered in this test. We proposed to perform calculations consequently for the three models of fuel assemblies: heterogeneous height with 1 fuel layer, with 5 fuel layers and fully heterogeneous model (Figure 3). The first two models are the model of the "flat" core. Boundary conditions corresponding to reflection are assign only on the sides of the fuel assembly, while leakage of neutrons will be in the ends of fuel assembly. Scenario of irradiating wos the same as in test 1.

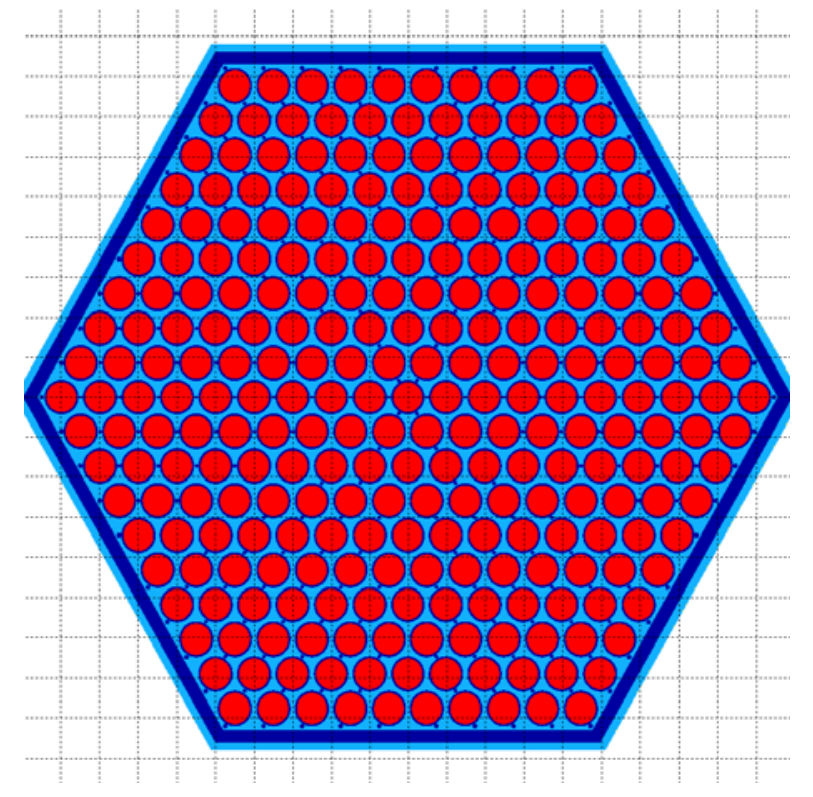

Fig. 3. Fuel assembly

\subsection{Test No. 3: active core}

This test was intended for simulation of reactor core of $\mathrm{BN}-1200$. Conventionally, the test was divided into two sub-tasks. The first subtask was stationary one. Multiplication factor was the main calculated characteristic. Scenario of irradiation was the same as in the previous two tests. The calculation model was composed of hexagonal cells with compositions corresponding to the locatet in the cells fuel assemblies. 
Seven types of fuel cells were selected radially to differ fuel compositions corresponding to the beginning of the cycle. Five axial zones with different fuel compositions were selected to consider different fuel burnup with the height of the core. The calculated model did not have an external zone of reproduction, raw material was admixed to the fuel assemblies of the core.

The second sub-task was intended for modeling of fuel recycle. Geometric model was the same as that described above. We supposed to calculate 60 fuel lifetimes in this test using the following algorithm of fuel load.

Duration of fuel lifetime was 360 days, including 330-days power operation and 30-days pause (Figure 2).

In the first three lifetimes, fuel assemblies with initial isotopic composition were loaded instead of discharged fuel assemblies. Discharged fuel assemblies were placed in 2-year intrareactor interim storage for cooling. Neutron fluxes in interim storage were assumed to be negligible. The duration of the external fuel cycle including reprocessing of fuel assemblies and the formation of a new load was assumed 1 year.

Beginning with the 4th lifetime, fuel loads were formed from the reprocessed fuel. Criticality for each lifetime provided by the choice of the mass fraction of plutonium. We considered 60-degree rotational symmetry of fuel assemblies, which was obtained from the real 360-degree schema of the load to reduce the computational expenses.

\section{Calculated functionals}

The following functionals were calculated in these tests: the effective multiplication factor, the isotopic composition in the end of fuel lifetime and after cooling, neutron induced reaction rates, temperature Doppler effect on fuel and steel, density factor for fuel and sodium, change of the reactivity with the fuel burnup, fuel reproduction parameters.

Analyzing the results of these calculations of test tasks, we can estimate an influence of the main sources of uncertainty on the error of neutron-physics calculations. Particular attention should be paid to the influence of the diffusion approximation, homogenization of fuel assemblies, and use of different constant libraries.

The developed system of test tasks can be used for verification of program codes for neutron-physical calculations that will improve the quality and reduce the time of certification of specialized code complexes.

\section{Test results}

\subsection{Program codes for calculations}

MMKKENO is program to calculate nuclear reactors by Monte Carlo method in multigroup approximation with scattering indicatrix in the $\mathrm{P}_{\mathrm{n}}-$ approximation. The program includes modified geometric modules from the program MMKFK HRAN, OOBHEX and HEXBL. The program is designed to calculate the physical characteristics of nuclear reactor in the threedimensional geometry. Program can calculate the following key characteristics: the effective multiplication factor; group fluxes; density of fissions; group absorption, fission, and leakage. The program has a number of possibilities, which require special skills and knowledge. One of these possibilities is introduction of areas with different value of neutrons. It allows to focus higher share of drawn neutron trajectories in areas with high value of neutrons. It also enables to use differential albedo, allowing to avoid the draw of neutron trajectories in the reflector. Use of these capabilities when solving criticality task allows to save computation time. However, the lack of experience may cause serious errors in the results.

$\mathrm{MCU}$ is a program aimed at modeling the transport of neutrons, gammas, electrons, and positrons in different three-dimensional systems by the Monte Carlo method. The program is under development during the period since 1982. Package MCU has a modular structure. Today the latest version of the package is MCU 5. This version contains the following modules: physical module, geometric module, source module, registration module, transport module, control module, burnup module, and others. Program uses each of the modules at certain calculation stage. The user creates an input file for calculation tasks, which looks like a set of text commands. In addition to single-processor mode, multiprocessor mode of calculation is possible. The paralleling is based on software Message Passing Interface (MPI). It should be noted that at the stage of calculation, each processor gets its own independent sequence of random numbers that does not overlap with sequences from other processors. An important step of calculation is the choice of libraries of evaluated nuclear data and the optimal scheme of operation of the submodules.

JARFR is a set of programs designed for threedimensional calculation of neutron-physical characteristics of nuclear reactors in the multi-group diffusion approximation of neutron transport equation. The system of preparation of neutron-physical constants CONSYST/PRECONS based on libraries BNAB-93 and BNAB-RF is used as system of constants. The complex of programs JARFR is certified by Gosatomnadzor for neutron-physical calculations of fast reactors and implemented in a number of organizations. The program was developed by Scientific Research Center "Kurchatov Institute".

TRIGEX is a set of programs designed for serial (engineering) calculations of neutron-physical characteristics of fast reactors [5]. A set of programs uses internal program CONSYST to prepare constants. To use the obtained constants in the diffusion code TRIGEX, diffusion coefficient is calculated in this code by means of the transport approximation with the possibility of a convolution with the zero or first harmonic.

TDMCC (Time dependent Monte Carlo Code) is a program realizing a method of Monte-Carlo. This multipurpose program can solve the tasks of evaluation of 
criticality and nuclear safety of both individual assemblies and active cores of the reactor plants, to evaluate radiation safety, to calculate the protection from radiation, to choose the parameters in order to obtain the specified value of the multiplication factor, and to perform calculations of fuel burnup and model fuel cycles of reactor installations. The program was developed in Russian Federal Nuclear Center - VNIIEF.

The multi-group calculation methods for fast reactors require the libraries of group cross sections covering practically the entire energy region from a few electron volts up to $15 \mathrm{MeV}$. The work on the preparation of group constants for fast reactors in our country was carried out in IPPE in Obninsk under the leadership of I. I. Bondarenko and M. N. Nikolaev. The system of constants $\mathrm{BNAB}$ is currently the main cross-section library, which is used in most calculations of fast reactors. The system of constants is periodically improved and updated with cross sections of new nuclides. Format of library of constants BNAB and its data are widely used abroad for calculation of reactors. The main advantage of this system is the ability of correct account of the resonance effects using the coefficients of self-shielding of cross sections.

\subsection{The results of testing on model of fuel element (Test No. 1)}

The development of the system of test tasks provided a possibility to begin cross-verification of programs for neutron-physical calculation used for the design of innovative reactor plants of new generation. This paragraph deals with the results of cross-verifications of engineering programs (JARFR and TRIGEX) and programs that provide the solution of neutron transport equation by Monte-Carlo method (MCU, SCALE MMK, and TDMCC).

Test task No. 1 includes significant number of different variants of initial load. This paragraph presents the results of one of them. We considered the following functionals: Keff, the composition of unloaded fuel, reaction rates, etc. Values of these functionals calculated by each program were compared with average values over all programs. Difference between average value and separate value divided by average value was the respective deviation of this value. We will below refer to them simply as deviations having in view respective deviations.

Table 1 presents deviation of multiplication factor. Table 2 presents deviations of the compositions of unloaded fuel after 3240 days ( 9 years). Table 3 presents deviations of the rate of fission reaction, and table 4 presents deviations of reaction rate of capture.

According to the results of this work we can conclude about the influence of the diffusion approximation. An attention should be payed on the changes in deviations during a time. This is due to the difference of the chains of nuclide transformation incorporated and implemented in programs.
Table 1. Deviations of multiplication factor in Test No.1, $\% \Delta \mathrm{k} / \mathrm{k}$

\begin{tabular}{|l|c|c|c|c|c|}
\hline \multirow{2}{*}{$\begin{array}{l}\text { Moment } \\
\text { of time }\end{array}$} & \multicolumn{5}{|c|}{ Progtams } \\
\cline { 2 - 6 } & MCU & $\begin{array}{c}\text { SCALE } \\
\text { - MMK }\end{array}$ & TDMCC & JARFR & TRIGEX \\
\hline $\begin{array}{l}\text { Beginning } \\
\text { of cycle }\end{array}$ & $-0,45$ & 0,18 & $-0,53$ & 0,3 & 0,49 \\
\hline $\begin{array}{l}\text { End of } \\
\text { 360-day } \\
\text { lifetime }\end{array}$ & $-0,51$ & $-0,01$ & - & 0,4 & 0,12 \\
\hline $\begin{array}{l}\text { End of } \\
\text { 9-yr cycle }\end{array}$ & $-0,29$ & 0,34 & - & 0,09 & $-0,14$ \\
\hline
\end{tabular}

Table 2. Deviations of fuel burnup inTest No. 1, \%

\begin{tabular}{|c|c|c|c|c|}
\hline \multirow{2}{*}{ Nuclide } & \multicolumn{4}{|c|}{ Program } \\
\cline { 2 - 5 } & MCU & SCALE - MMK & JARFR & TRIGEX \\
\hline${ }^{238} \mathrm{U}$ & $-0,12$ & 0,08 & 0,08 & $-0,05$ \\
\hline${ }^{238} \mathrm{Pu}$ & $-3,81$ & $-0,35$ & 6,77 & $-1,98$ \\
\hline${ }^{239} \mathrm{Pu}$ & 0,16 & 0,26 & $-0,32$ & $-0,09$ \\
\hline${ }^{240} \mathrm{Pu}$ & $-0,53$ & $-1,94$ & 1,13 & 1,42 \\
\hline${ }^{241} \mathrm{Pu}$ & 8,32 & 1,66 & $-11,54$ & 3,87 \\
\hline${ }^{242} \mathrm{Pu}$ & $-0,68$ & $-1,21$ & 0,87 & 1,05 \\
\hline Sum U & $-0,12$ & 0,14 & 0,01 & $-0,04$ \\
\hline Sum $\mathrm{Pu}$ & 0,1 & $-0,23$ & $-0,23$ & 0,37 \\
\hline Sum $\mathrm{HM}$ & $-0,1$ & 0,02 & 0,02 & 0,06 \\
\hline
\end{tabular}

Table 3. Deviations of fission rate in Test No. 1, \%

\begin{tabular}{|c|c|c|c|c|}
\hline \multirow{2}{*}{ Nuclide: } & \multicolumn{4}{|c|}{ Program } \\
\cline { 2 - 5 } & MCU & $\begin{array}{c}\text { SCALE - } \\
\text { MMK }\end{array}$ & JARFR & TRIGEX \\
\hline${ }^{235} \mathrm{U}$ & 1,33 & $-1,17$ & 0 & $-0,2$ \\
\hline${ }^{238} \mathrm{U}$ & $-4,26$ & 2,39 & 0,75 & 0,87 \\
\hline${ }^{238} \mathrm{Pu}$ & $-2,48$ & 1,85 & 0,05 & 0,48 \\
\hline${ }^{239} \mathrm{Pu}$ & 0,67 & $-0,35$ & $-0,05$ & $-0,28$ \\
\hline${ }^{240} \mathrm{Pu}$ & $-1,38$ & 2,89 & $-0,97$ & $-0,65$ \\
\hline${ }^{241} \mathrm{Pu}$ & 1,14 & $-1,54$ & 0,09 & 0,27 \\
\hline${ }^{242} \mathrm{Pu}$ & $-3,11$ & 5,04 & $-1,31$ & $-1,01$ \\
\hline
\end{tabular}


Table 4. Deviations of capture rate in Test No. 1, \%

\begin{tabular}{|c|c|c|c|c|}
\hline \multirow{2}{*}{ Nuclide } & \multicolumn{4}{|c|}{ Progran } \\
\cline { 2 - 5 } & MCU & $\begin{array}{c}\text { SCALE - } \\
\text { MMK }\end{array}$ & JARFR & TRIGEX \\
\hline${ }^{235} \mathrm{U}$ & 0,89 & 2,69 & $-1,71$ & $-2,01$ \\
\hline${ }^{238} \mathrm{U}$ & $-0,27$ & $-0,58$ & 0,56 & 0,28 \\
\hline${ }^{238} \mathrm{Pu}$ & 3,5 & 14,42 & $-11,5$ & $-11,32$ \\
\hline${ }^{239} \mathrm{Pu}$ & 1,45 & $-0,93$ & 0,01 & $-0,56$ \\
\hline${ }^{240} \mathrm{Pu}$ & $-4,11$ & 0,71 & 1,82 & 1,35 \\
\hline${ }^{241} \mathrm{Pu}$ & 4,17 & 3,97 & $-4,29$ & $-4,58$ \\
\hline${ }^{242} \mathrm{Pu}$ & 0,04 & $-2,91$ & 1,6 & 1,15 \\
\hline $\mathrm{N}$ & 4,96 & 3,48 & $-4,94$ & $-4,3$ \\
\hline $\mathrm{Na}$ & 5,15 & $-0,45$ & $-2,29$ & $-2,83$ \\
\hline $\mathrm{Fe}$ & $-0,33$ & $-0,06$ & 0,04 & 0,35 \\
\hline $\mathrm{Ni}$ & 1,03 & $-5,23$ & 1,83 & 2,02 \\
\hline $\mathrm{Mo}$ & 1,28 & $-0,09$ & $-0,57$ & $-0,64$ \\
\hline $\mathrm{Nb}$ & 4,17 & $-12,35$ & 3,41 & 3,02 \\
\hline $\mathrm{Mn}$ & $-1,27$ & $-10,87$ & 5,7 & 4,78 \\
\hline
\end{tabular}

\subsection{The results of testing on model of fuel assembly (Test No. 2)}

According to the developed system of test task, crossverification of programs on the model of fuel element should be followed by their comparison on the model of fuel assembly. Test No. 2 deals with calculations on model of fuel assembly. This paragraph presents the results of the comparison calculations by the following programs: MCU, JARFR, SCALE-MMK and TRIGEX.

We performed comparison using following parameters: the dependence of the multiplication factor on time, the composition of unloaded fuel, reaction rates, etc. Table 5 presents the deviations of the multiplication factor. We see that deviation does not exceed $1 \%$. For a given accuracy of calculations, this deviation demonstrates good agreement between the results of calculations obtained by different programs.

Table 5. Deviations of multiplication factor in Test No. 2 $\% \Delta \mathrm{k} / \mathrm{k}$

\begin{tabular}{|l|c|c|c|c|}
\hline \multirow{2}{*}{$\begin{array}{l}\text { Moment } \\
\text { of time }\end{array}$} & \multicolumn{4}{|c|}{ Program } \\
\cline { 2 - 5 } & MCU & $\begin{array}{c}\text { SCALE - } \\
\text { MMK }\end{array}$ & JARFR & TRIGEX \\
\hline $\begin{array}{l}\text { Beginning } \\
\text { of cycle }\end{array}$ & $-0,59$ & $-0,24$ & 0,37 & 0,45 \\
\hline $\begin{array}{l}\text { End of } \\
\text { 360-day } \\
\text { lifetime }\end{array}$ & $-0,69$ & - & 0,32 & 0,36 \\
\hline $\begin{array}{l}\text { End of 9-yr } \\
\text { cycle }\end{array}$ & $-0,23$ & $-0,12$ & 0,21 & 0,15 \\
\hline
\end{tabular}

Table 6 presents deviations of the rates of fission and table 7 presents deviations of the rates of capture.

Table 6. Deviations of fission rates in Test No. 2, \%

\begin{tabular}{|c|c|c|c|c|}
\hline \multirow{2}{*}{ Nuclide } & \multicolumn{4}{|c|}{ Programs } \\
\cline { 2 - 5 } & MCU & $\begin{array}{c}\text { SCALE - } \\
\text { MMK }\end{array}$ & JARFR & TRIGEX \\
\hline${ }^{235} \mathrm{U}$ & 2,34 & $-0,99$ & $-0,61$ & $-0,8$ \\
\hline${ }^{238} \mathrm{U}$ & $-4,58$ & 1,96 & 3,51 & $-1,27$ \\
\hline${ }^{238} \mathrm{Pu}$ & $-2,26$ & 1,55 & 1,02 & $-0,4$ \\
\hline${ }^{239} \mathrm{Pu}$ & 1,07 & $-0,2$ & $-0,2$ & $-0,68$ \\
\hline${ }^{240} \mathrm{Pu}$ & $-1,53$ & 2,33 & 0,92 & $-1,84$ \\
\hline${ }^{241} \mathrm{Pu}$ & 2,2 & $-0,93$ & $-0,4$ & $-0,93$ \\
\hline${ }^{242} \mathrm{Pu}$ & $-3,42$ & 4,21 & 1,23 & $-2,39$ \\
\hline
\end{tabular}

Table 7. Deviations of capture rates in Test No. 2, \%

\begin{tabular}{|c|c|c|c|c|}
\hline \multirow{2}{*}{ Nuclide } & \multicolumn{4}{|c|}{ Programs } \\
\cline { 2 - 5 } & MCU & $\begin{array}{c}\text { SCALE - } \\
\text { MMK }\end{array}$ & JARFR & TRIGEX \\
\hline${ }^{235} \mathrm{U}$ & 2,56 & 3,73 & $-3,4$ & $-3,32$ \\
\hline${ }^{238} \mathrm{U}$ & 0,86 & $-0,23$ & $-0,51$ & $-0,12$ \\
\hline${ }^{238} \mathrm{Pu}$ & 5,62 & 15,33 & $-13,96$ & $-13,39$ \\
\hline${ }^{239} \mathrm{Pu}$ & 3,62 & 0,72 & $-2,54$ & $-2,05$ \\
\hline${ }^{240} \mathrm{Pu}$ & $-1,53$ & 2 & $-0,33$ & $-0,21$ \\
\hline${ }^{241} \mathrm{Pu}$ & 6,22 & 5,24 & $-6,27$ & $-6,68$ \\
\hline${ }^{242} \mathrm{Pu}$ & 2,68 & $-1,61$ & $-0,38$ & $-0,8$ \\
\hline
\end{tabular}

\section{Conclusions}

System of test task is developed. Fast neutron BN-1200 reactor with nitride fuel was prototype for these tasks. The system of test task consists of three sequential tests based on different geometric models: fuel element, fuel assembly, and the active core. This system was used in independent testing of programs for calculation of neutron-physical characteristics: engineering programs JARFR and TRIGEX, and codes MCU, TDMCC, and MMK based on the method of Monte Carlo.

We selected following main functionals for crossverification of codes: the effective multiplication factor, the change in isotopic composition of fuel during burnup, and rates of capture and fission reactions.

Analysis of the results of calculations of test tasks and their comparison allows to estimate the influence of the main sources of uncertainty on the accuracy of neutron-physical calculations.

The system of test task presented in this paper may be used in the verification of programs for neutronphysical calculations, which can be applied for the design and exploiting of new generation reactors. 


\section{References}

1. IAEA-TECDOC-1623. February, 2010.

2. S. Belov, M. Farakshin, Working Material of the Research Coordination Meeting, Vienna, 20-24 November 2000. IAEA-RC-803.2. IWG-FR/103, 274-324.

3. J. Tommasi, Proposal for a benchmark on EFR calculations (SPRC/LEDC).

4. The comparaison of calculational results of efrbenchmark obtained by M. Semenov, J Tommasi, A. Zaetta, AIDA-MOX Theme 2. Utilization of Weapon Grade Plutonium in Reactor. Obninsk, Russia, April 24th-29th 1994.

5. A. Danilychev, A. Seregin, V. Stogov, Working Material of the Research Coordination Meeting, Vienna, 20-24 November 2000. IAEA-RC-803.2. IWG-FR/103, 342-345 